10.1590/S1414-40772018000300016

Este é um artigo publicado em acesso aberto sob uma licença Creative Commons

https://creativecommons.org/licenses/by-nc/4.0/

\title{
Capital e Poder a serviço da Globalização: os oligopólios da educação superior privada no Brasil
}

\author{
Andreia Gomes da Cruz ${ }^{1}$ \\ Maria de Fátima Costa de Paula ${ }^{2}$
}

Resumo: O artigo tem como finalidade problematizar o surgimento dos oligopólios da educação superior privada que emergem como consequência do processo de reconfiguração da educação superior brasileira em decorrência da adoção de políticas públicas de viés neoliberal na década 1990, que ocorrem como resultado de profundas transformações no campo da Educação, no Brasil. Diante deste processo presencia-se o início das fusões, formando grandes conglomerados educacionais, resultando na financeirização do ensino superior. O estudo detecta um movimento que vem ocorrendo em que o processo capitalista de acumulação favorece a formação de conglomerados, cujo poder econômico rege um segmento que deveria ser gerido pelo Estado.

Palavras-chave: Educação superior privada. Mercadorização da educação. Oligopólios da Educação superior.

\section{Capital and Power in the service of Globalization: oligopolies of private higher Education in Brazil}

Abstract: The article aims to discuss the emergence of oligopolies in private higher education that have arisen as the result of the reconfiguration of the Brazilian process on higher education to the adoption of public policies of neoliberal bias in the 1990s, and produced as the result of profound changes in the field of education in Brazil. This process is the beginning of mergers, the formation of large conglomerates educational, resulting financialization of university education. The study detects a movement that has occurred so that the process of capitalist accumulation favors the formation of conglomerates whose economic power governs a segment that should was be administered by the State.

Key words: Education commodification. Oligopolies. Private higher education. 


\section{Introdução}

Nas últimas décadas, a política educacional brasileira tem passado por alterações significativas, que devem ser analisadas à luz da crise e da reestruturação do Estado - o ajuste econômico de corte neoliberal, que emergiu nos países desenvolvidos e, posteriormente, atingiu a América Latina.

O projeto neoliberal, no entanto, brasileiro trouxe uma proposta ainda mais crucial: a desregulamentação da economia que, na verdade, representaria o fim da regulamentação do Estado sobre os preços e sobre a relação capital-trabalho. As consequências de tal ação foram as privatizações, feitas sob a alegação de redução de gastos com o setor público, medidas que tiveram como prerrogativa a "incompetência e a ineficácia do setor público" para gerir negócios, que difere da racionalidade eficiente do setor privado.

Podemos, então, dizer que, no setor educacional, as políticas adotadas pelo Estado vêm sofrendo drásticas transformações, e que o discurso em prol da educação ganha novo ângulo, ou seja, que nessa perspectiva ela deixa de ser entendida como direito do cidadão e dever do Estado e passa a ser vista como mercadoria e, como tal, objeto de compra e venda. Essas mudanças educacionais, que a sua vez acompanham as políticas econômicas, atendem a diretrizes do Banco Mundial (BM), do Fundo Monetário Internacional (FMI) e da Organização Mundial do Comércio (OMC).

Essas novas orientações vieram desencadear novos rearranjos na educação superior brasileira, principalmente na educação superior privada, que inaugura uma nova fase de expansão. Esse processo, que vai se aprofundar com as fusões que formam conglomerados educacionais, com ênfase na financeirização das instituições de ensino superior e, desse modo, expõe a educação nacional a um intenso processo de desnacionalização.

Nesse sentido, a expansão da educação brasileira intensificou-se, especialmente no Governo Fernando Henrique Cardoso (FHC), com suas ações, tendo permitido junto a intensificação da privatização do ensino superior, por meio de leis e decretos que contribuíram legal e significativamente para a expansão desenfreada desses institutos, faculdades e universidades privadas, principalmente porque esse processo expansionista fez parte da reforma do Estado implementada no País, a partir da década de 1990 (SILVA JUNIOR; SGUISSARDI, 2001; CHAVES, 2010). Enquanto isso as instituições públicas sofreram um drástico corte orçamentário, ficaram anos sem concurso público e, principalmente, ainda tiveram que se "adaptar" à lógica neoliberal. A inserção das universidades públicas na lógica racionalizadora do capital (PAULA, 2002), trouxe como 
consequências a sua privatização interna, significando a mercantilização do ensino, no âmbito da formação universitária, da pesquisa e da extensão (PAULA, 2003, p. 54).

Assim, no octênio FHC, ocorre a promulgação da Lei de Diretrizes e Bases da Educação Nacional n. ${ }^{\circ}$ 9.394/1996, que permite que instituições privadas ofereçam cursos de pós-graduação stricto sensu mediante a contrapartida financeira por parte dos alunos. Além disso, Cunha (2004) vai apontar que essa legislação educacional foi bastante permissiva com as instituições privadas, tanto nas determinações quanto nas suas "omissões". Nesse sentido, a LDB é apontada como marco legal da reforma que foi colocada em curso na década de 1990, pela qual o Estado assume o controle e a gestão das políticas públicas. Assim, o Estado é o máximo gestor no que refere à avaliação e ao controle das IES, mas é o mínimo no que se refere ao financiamento das IES públicas, liberando a oferta da educação superior para a iniciativa privada, conforme vemos a seguir:

Art. $7^{\circ}$ : $\mathrm{O}$ ensino é livre à iniciativa privada, atendidas as seguintes condições: I - cumprimento das normas gerais da educação nacional e do respectivo sistema de ensino; II- autorização de funcionamento e avaliação de qualidade pelo Poder Público; III - capacidade de autofinanciamento, ressalvado o previsto no art. $213^{1}$ da Constituição Federal (BRASIL, LDB, 1996, grifos nossos).

Outra problemática no tocante a LDB está relacionada à diversificação e diferenciação institucional, consubstanciada também em outros dispositivos legais como os Decretos n. ${ }^{\text {o }}$ 2.306/1997 (BRASIL.MEC, 1997) ${ }^{2}$ e n. ${ }^{\circ}$ 3.860/2001 ${ }^{3}$. Enquanto o primeiro decreto determinava a natureza civil ou comercial, o segundo teve como objetivo complementar a legislação anterior, ou seja, exigiu que as instituições sem fins lucrativos ${ }^{4}$ apresentem "a

1 Art. 213. Os recursos públicos serão destinados às escolas públicas, podendo ser dirigidos a escolas comunitárias, confessionais ou filantrópicas, definidas em lei, que I - comprovem finalidade não-lucrativa e apliquem seus excedentes financeiros em educação; II - assegurem a destinação de seu patrimônio a outra escola comunitária, filantrópica ou confessional, ou ao Poder Público, no caso de encerramento de suas atividades. $\S 1^{\circ}$ - Os recursos de que trata este artigo poderão ser destinados a bolsas de estudo para o ensino fundamental e médio, na forma da lei, para os que demonstrarem insuficiência de recursos, quando houver falta de vagas e cursos regulares da rede pública na localidade da residência do educando, ficando o Poder Público obrigado a investir prioritariamente na expansão de sua rede na localidade. $\S 2^{\circ}$ - As atividades universitárias de pesquisa e extensão poderão receber apoio financeiro do Poder Público. Disponível em: <http://portal.mec.gov.br/setec/arquivos/pdf_legislacao/ superior/legislasuperiorconst.pdf>. Acesso em: dez. 2014.

${ }^{2}$ Regulamenta, para o Sistema Federal de Ensino, as disposições contidas no art. 10 da Medida Provisória $\mathrm{n}^{\circ}$ 1.477-39, de 8 de agosto de 1997, e nos Art. 16, 19, 20, 45, 46 e $\S 1^{\circ}, 52$, parágrafo único, 54 e 88 da Lei $n^{\circ}$ 9.394, de 20 de dezembro de 1996, e dá outras providências. Disponível em: <http://www.planalto.gov.br/ccivil_03/decreto/D2306.htm>. Acesso: dez. 2014.

${ }^{3}$ Dispõe sobre a organização do ensino superior, a avaliação de cursos e instituições, e dá outras providências. Disponível em: <http://www.planalto.gov.br/ccivil_03/decreto/2001/D3860.htm > Acesso: dez.2014.

${ }^{4}$ Segundo MEC, a instituição Privada com fins lucrativos - instituição mantida por ente privado, com fins lucrativos; sem fins lucrativos não beneficente - instituição mantida por ente privado, sem fins lucrativos; pode ser confessional ou comunitária, conforme o Art. 20 da LDB; beneficente: instituição mantida por ente 
publicação anual de suas demonstrações financeiras certificadas por auditores independentes do conselho fiscal; a escrituração de todos os seus dados ficais em livros” (BARREYRO, 2008, p. 21).

Desse modo, entendemos que, para dar prosseguimento a essa política, as instituições privadas de educação superior foram incentivadas a expandir seu sistema, via liberação de serviços educacionais e isenção fiscal, "em especial, da oferta de cursos aligeirados, voltados apenas para o ensino desvinculado da pesquisa" (CHAVES, 2010, p. 483).

Nesse sentido, concordamos com Chaves (2010, p. 490) quando afirma que a LDB contribuiu para a emergência e a consolidação de instituições como empresas com fins lucrativos e, mais do que isso,

[a] liberalização e a desregulamentação desse setor, com a flexibilização das regras para abertura de cursos e novas instituições, as isenções tributárias, as bolsas de estudos para alunos carentes, por meio do programa de Crédito Educativo, hoje transformado no Fundo de Financiamento ao Estudante do Ensino Superior (FIES), os empréstimos financeiros a juros baixos por instituições bancárias oficiais, como o Banco Nacional de Desenvolvimento Econômico e Social (BNDES), o PROUNI, entre outras formas de estímulo, contribuíram de forma decisiva para expansão da mercantilização do ensino superior (grifos nossos).

É importante destacar, nesse sentido, que a política de privatização da educação superior em curso no País, é evidenciada nos dados do Resumo Técnico - Censo da Educação Superior (2014), com a predominância da categoria privada em 74,9\% do total das IES, enquanto as públicas registram apenas $25,1 \%$. Em relação ao quantitativo de matrículas da graduação foi atingido um total de 7.828.013 milhões, sendo que para as IES privadas o total é de 5.373.450 milhões, enquanto que nas IES públicas o total é de 1.961 .002 milhões.

Outro dado divulgado no resumo está relacionado à organização acadêmica, de que as faculdades totalizam 1.986 estabelecimentos, correspondendo a 83,9\%, num total de 2.368 IES, mas concentram $28,6 \%$ das matrículas. As universidades representam $8,2 \%$ num total de 2.368, mas concentram 53,2\% das matrículas, pois elas incluem pesquisa e extensão; já os centros universitários representam 6,2\% e concentram 16,5\% das matrículas; e Institutos Federais (IF) e Centro de Educação Federal Tecnológica (CEFET), 1,7\%, com 1,7\% das matrículas.

privado, sem fins lucrativos, detentora de Certificado de Assistência Social, nos termos da legislação própria. Pode ser confessional ou comunitária. Especial (Art. 242 da Constituição Federal) - instituição educacional oficial criada por lei estadual ou municipal e existente na data da promulgação da Constituição Federal, que não seja total ou preponderantemente mantida com recursos públicos, portanto não gratuita. Disponível em: <http://www.dce.mre.gov.br/nomenclatura_cursos.html>. Acesso: dez. 2014. 
Esses dados vão trazer novas configurações para a educação superior, uma vez que instituições, denominadas universidades corporativas, serão compostas por empresas multinacionais, como FIAT, FORD, IBM, McDonald's, principalmente oportunizando a criação de oligopólios, pois tais instituições sendo empresas de capital aberto negociam suas ações nas Bolsas de Valores. Esse processo vem movimentando um capital de "15 bilhões de reais por ano, e quando se olha o universo de alunos potenciais, vê-se que a possibilidade de crescimento é impressionante" (ERTHAL; PEROSIM, 2007, grifos nossos).

Confirmando tal potencialidade, Leher (2005) afirma que esse segmento é extraordinário, e por isso as grandes universidades fazem associações com o objetivo de "entrar" nesse "magnífico mercado". E o melhor segmento - todas as grandes empresas do setor fazem a mesma avaliação -, está concentrado no ensino superior e na formação continuada (LEHER, 2005).

Então, concorda-se com Oyama (2012, p. 93) quando afirma que o processo de mercantilização ocorre por meio de mecanismos complexos, especialmente porque contam com a participação de organismos multilaterais. Esse processo, portanto, envolve estímulos "conscientes e voluntários da expansão e do aumento da educação superior privada em detrimento da pública, visando claramente à exploração e à obtenção de lucros com o mercado educacional privado brasileiro".

Desse modo, radiografar o setor privado de educação superior no Brasil permite compreender como e quanto é paradoxal a situação da educação superior em nosso país, principalmente quando conhecemos as razões dos altos índices de privatização nesse nível de ensino.

\section{Os Oligopólios da educação superior privada no Brasil}

Podemos afirmar que o processo de mercadorização da educação brasileira tem como causa a grande presença da iniciativa privada no ensino superior, e isso fez com que se delineassem [...] "novos contornos por meio da compra e venda de instituições de ensino, fusões formando grandes oligopólios e pela abertura de capital na bolsa de valores" (SGUISSARDI, 2008, p. 1012). Ratificando esse pensamento, Bittar e Ruas (2012) vão apontar que a mercadorização da educação superior em nosso país foi intensificada em virtude de inserção da sociedade brasileira numa economia competitiva e globalizada.

Nesse sentido, também, Bittar e Ruas (2012, p. 125) afirmam que esses oligopólios “são formados por empresários que mantêm vínculos com grandes bancos de investimentos 
norte-americanos que entraram no país, investindo enormes cifras para garantir sua presença nas IES brasileiras". Além disso, destacamos que o processo de financeirização da educação superior, promovido em virtude das negociações atreladas ao setor mercantil, favoreceu consideravelmente esse setor, uma vez que "esse movimento de permanente expansão propiciou a penetração do capital financeiro na educação superior brasileira, provocando a internacionalização da oferta educacional” (BITTAR; RUAS, 2012, p. 123).

Assim, temos observado nas últimas décadas um forte movimento de compra e venda de instituições de educação superior privadas, movimentando vultosas somas. Uma das primeiras iniciativas surge em 2001 quando o grupo Pitágoras de Minas Gerais, fundado por Walfrido dos Mares Guia Neto em 1996 fecha uma parceria com Apollo Internacional (sediada em Arizona, EUA); é importante destacar que essa parceria entre os grupos Pitágoras e Apollo durou até 2005, quando a Apollo Internacional decidiu vender a sua participação aos fundadores. De acordo com informações contidas no próprio site do grupo, em 2007, o Pitágoras origina o grupo Kroton Educacional e, nesse mesmo ano, ocorre também sua abertura do capital. Isto possibilitou (vide site) "a consolidação de uma fase de grande expansão e desenvolvimento da companhia". Além disso, em 2009, Kroton recebeu um novo aporte financeiro de um dos maiores fundos de private equity ${ }^{5}$ (MEIRELLES; PIMENTA JUNIOR; REBELATTO, 2008, p. 13) do mundo, a Advent Internacional, que passou a compartilhar o controle da companhia com os sócios fundadores.

A Anhanguera Educacional foi a primeira instituição de educação superior a ter ações negociadas na Bolsa de Valores, tornando-se a primeira IES privada da América Latina a abrir seu capital e que, ao passar por esse processo, abriu caminho para outras IES brasileiras como as do grupo Kroton, as do Sistema Brasileiro (SEB) e a Estácio de Sá. No demonstrativo financeiro de 2012, os números apontam para uma evolução operacional que proporcionou um "robusto" desempenho a essa instituição, como pode ser evidenciado nos dados a seguir:

Com uma receita líquida de $\mathrm{R} \$ 1,4$ bilhão, um EBITDA ajustado ${ }^{6}$ de $\mathrm{R} \$ 387,6$ milhões (mais de 3 vezes o apresentado em 2011), uma margem EBITDA ajustada de 27,6\% e um lucro líquido

5 Venture capital e Private equity (VC/PE) são segmentos do mercado financeiro que consistem fundamentalmente em aporte temporário de capital, realizado por fundo de $\mathrm{VC} / \mathrm{PE}$, por meio de participação no capital de empresas com potencial de crescimento e expectativa de grande valorização. A valorização da empresa permitirá ao fundo de VC/PE obter retorno com a venda da participação (desinvestimento) a médio e longo prazo.

${ }^{6}$ EBITDA ajustado é o lucro líquido antes dos impostos, das despesas financeiras líquidas, das despesas de depreciação e amortização, e do resultado da venda de veículos. O EBITDA ajustado apresentado é utilizado pela Companhia para medir a sua própria performance. Disponível em: 
ajustado de $\mathrm{R} \$ 268,0$ milhões, consolidamos a Kroton em um novo nível de rentabilidade, superando, inclusive, o guidance $e^{7}$ divulgado. [...]. Além disso, vale destacar a geração de caixa operacional no período alcançou mais de $\mathrm{R} \$ 314,2$ milhões. Isso só foi possível pelos constantes esforços colocados em prática por nossos quase 15 mil funcionários na busca da melhor eficiência e da oferta de uma educação responsável e de alta qualidade a todos os nossos alunos (KROTON EDUCACIONAL S.A CONTROLADAS, 2012, p. 10).

Chaves (2010) anota que, a partir de 2005, a Kroton passa a oferecer cursos de curta duração para formação para tecnólogos (30 meses), com a marca "INED”. Além disso, destacamos que essa empresa se transformou em um gigante no campo da educação superior, pois encerrou o ano de 2012 com 410.035 alunos, sendo 371.519 matriculados em cursos de graduação (presencial e a distância). Outro destaque do relatório expõe que houve um crescimento no número de alunos no ensino superior de $62 \%$ em relação a 2011 , em virtude principalmente tanto da aquisição, em 2012, da Uniasselvi, quanto do crescimento orgânico do negócio (grifos nossos), ou seja, a conquista de novos alunos. Os tentáculos dessa instituição não se restringem à educação superior, fazendo-se presente também na educação básica, através da Rede Pitágoras, com 810 Escolas Associadas e aproximadamente 300 mil estudantes, o que vai corresponder a um crescimento de 2,5\% em relação a 2011.

Outro grande conglomerado que segue esse mesmo modelo é o Sistema COC de Educação e Comunicação que, em 2000, expandiu seus negócios para a educação superior, através das Faculdades COC, com cursos de graduação presenciais; em 2005, amplia sua oferta de serviços educacionais com cursos na modalidade a distância. Posteriormente, em 2007, a rede passa a ser chamada de Sistema Educacional Brasileiro (SEB), ingressando no mercado de capitais, negociando suas ações na Bolsa de Valores de São Paulo (BOVESPA).

Para Chaves (2010, p. 494) a abertura do capital operou um forte processo expansionista, tendo como consequência a compra da Faculdade Metropolitana, de Belo Horizonte (MG), da Faculdade Dom Bosco, de Curitiba (PR), sendo que, já em 2010, a "sua maior atuação se faz por meio da EAD, com 19.875 alunos matriculados em cursos de graduação semipresenciais (com encontros presenciais semanais), na Faculdade Interativa COC".

Outro caso que merece atenção neste estudo é o da Anhembi Morumbi, fundada em 1970, e que foi a primeira faculdade brasileira a oferecer o curso superior de Turismo. Em

<http://ri.unidas.com.br/unidas/web/conteudo_pt.asp?idioma=0 \&conta=28\&tipo=13780>. Acesso em: dez. 2014.

${ }^{7}$ Pode ser definido como um conjunto de comentários que uma empresa faz a respeito das perspectivas para sua atividade. Disponível em: <http://www.infomoney.com.br/educacao/guias/noticia/429533/guidance-empresasdivulgando-perspectivas-para-seus-negocios>. Acesso em: dez. 2014. 
2005, de acordo com informações de seu site, a Universidade Anhembi Morumbi "fecha uma aliança com a Rede Internacional de Universidade Laureate", o que, na prática, significa que grupo norte-americano passou a ser dono de $51 \%$ das ações da universidade.

\section{Grupo dos EUA compra a Anhembi Morumbi}

Um grupo educacional dos Estados Unidos vai assumir o controle da Universidade Anhembi Morumbi, de São Paulo. A Laureate anunciou ontem que comprou 51\% da participação da universidade paulista. Até então, só uma instituição de ensino superior no Brasil, a Faculdade Pitágoras, de Minas Gerais, tinha como sócio um grupo estrangeiro. A transação da Anhembi Morumbi e da Laureate, no entanto, será a primeira no Brasil em que um grupo estrangeiro terá controle majoritário da instituição, já que, no caso da Pitágoras, o grupo Apollo (também dos Estados Unidos) divide o controle com o sócio brasileiro (cada um tem 50\% de participação no negócio). "Com 51\%, o grupo terá o poder de decisão na universidade", afirma o consultor de ensino superior Carlos Monteiro. De acordo com a notícia divulgada no site da Laureate, o valor da transação foi de US\$69 milhões ( $\$$ \$158 milhões). A Anhembi Morumbi possui 25 mil alunos de graduação. A universidade é a $22^{\mathrm{a}}$ maior entre as 1.859 instituições de ensino superior do país, segundo o último levantamento divulgado pelo MEC (GOIS; TAKAHASHI, Folha de S. Paulo, 02/12/2005).

Destacamos que a compra da Anhembi Morumbi não foi a única aquisição da Laureate, pois ela comprou também 90\% do Centro Universitário Hermínio (IB MR Centro Universitário), em 2010. Recentemente, as Faculdades Metropolitanas Unidas (FMU), juntamente com as demais instituições que fazem parte do complexo educacional Faculdades Integradas de São Paulo (FISP), as Faculdades Integradas Alcântara Machado e a Faculdade de Artes Alcântara Machado (FIAM-FAAM) foram também compradas pela Laureate, sendo a fusão noticiada pelos principais jornais no Brasil.

\section{Grupo americano, dono da Anhembi Morumbi, compra FMU por R\$1 bilhão}

Com a aquisição, que será anunciada oficialmente nesta sexta, a Laureate passa a contabilizar mais de 200 mil alunos no país. Uma das instituições de ensino superior privado mais cobiçado do mercado, a paulistana FMU, foi vendida por $\mathrm{R} \$ 1$ bilhão, para rede americana Laureate, que já é dona da Anhembi Morumbi. O negócio, que vinha sendo costurado há quase um ano, será anunciado oficialmente nesta sexta feira. Essa é a maior transação realizada no setor desde a fusão que criou, em abril, o maior grupo de educação superior no mundo, com a união de Kroton e Anhanguera. [...]. Americanos. Essa é a 12a aquisição da Laureate no Brasil. Os americanos entraram no Brasil em 2005, comprando uma fatia da Anhembi Morumbi, do professor Gabriel Rodrigues. O negócio é visto no setor como um dos primeiros na onda de consolidação que tomou conta do segmento de ensino superior privado no Brasil nos últimos anos - capitaneada por empresas controladas por fundos private equity. A própria Laureate, com 750 mil alunos em 29 países, tem entre seus sócios o megafundo de investimento americano KKR. [...]. (OSCAR; SOUSA, 2013).

A Whitney Internacional University System ${ }^{8}$ adquiriu $60 \%$ do capital da Faculdade Jorge Amado (Bahia), que posteriormente foi transformada em Centro Universitário Jorge Amado (UNIJORGE) e a rede DeVry University adquiriu 69\% da Faculdade Nordeste, sendo

\footnotetext{
${ }^{8}$ É uma rede universitária global com sede em Dallas, Texas (EUA). Além dos EUA, está presente na América Latina, Norte da África e Oriente Médio.
} 
que esta não foi a única instituição privada comprada pela rede DeVry, conforme reportagem a seguir.

\author{
DeVry Brasil amplia participação no Nordeste e chega a Recife com a Faculdade Boa \\ Viagem (FBV)
}

Recife (PE) - A DeVry Brasil anuncia um acordo pelo qual a Faculdade Boa Viagem* (FBV) passa a fazer parte do seu grupo de instituições educacionais. A FBV, instituição de ensino superior reconhecida no mercado pernambucano, conta atualmente com cerca de 5.800 alunos e oferece cursos de graduação, pós-graduação e mestrado em 3 campi na cidade de Recife. Com essa ação, a FBV passa a fazer parte de um dos maiores grupos educacionais do mundo. Esta operação é mais uma etapa do processo de ampliação da participação da DeVry na região Nordeste, onde o grupo já mantém atividades nos estados do Ceará e da Bahia. [...]. No Brasil, a DeVry já controla as faculdades Fanor, em Fortaleza (CE), e ÁREA1 e Ruy Barbosa, ambas localizadas na cidade de Salvador (BA). Ao todo, essas três unidades prestam serviços para 14 mil alunos em 33 cursos de graduação e mais de 20 cursos em pós-graduação, com foco nas áreas de Administração, Saúde, Direito e Engenharia. Todas as instituições da DeVry operam com elevados padrões de qualidade acadêmica e satisfação de seus alunos. (FBV, 2015).

Outras universidades foram compradas ou fusionadas: a GP Investimentos adquiriu 20\% das ações da Estácio de Sá, a UBC Pactual possui 38\% das Faculdades do Nordeste, a Fundo Pátria adquiriu 70\% do controle acionário da Anhanguera, Capital Group negocia ações no Grupo Kroton e Cartesian Group comprou parte do grupo nordestino Maurício de Nassau. Destacamos que todas essas transcrições foram noticiadas pelos jornais e outros meios de comunicação.

\title{
Da educação mercadoria à certificação vazia
}

[...] O ensino superior, público e privado, no Brasil, passou por grandes transformações nas últimas décadas. Essas mudanças - travestidas de democratização, por favorecerem o acesso visaram atender a uma proposta de privatização e barateamento da educação. A predominância de objetivos economicistas em detrimento dos pedagógicos nas IES privadas permitiu um fenômeno relativamente novo no Brasil: a formação de conglomerados educacionais, grandes empresas, de capital aberto e com forte participação de grupos estrangeiros em seu quadro de acionistas. A autorização para funcionamento dessa espécie de oligopólio do setor educacional tem intensificado a visão mercantil da educação superior no Brasil. Os exemplos mais representativos desse modelo de organização empresarial na educação ficam por conta dos grupos educacionais Kroton-Pitágoras, Estácio de Sá, SEB (Sistema Educacional Brasileiro) e Anhanguera Educacional. Esta última, com a recente aquisição da Uniban, passou a ser o maior grupo educacional do país, atendendo aproximadamente 400 mil alunos em campi espalhados por diversos estados brasileiros. Além disso, manteve sua projeção de crescimento de atingir 1 milhão de estudantes em cinco anos, segundo matéria do Valor Econômico de 17 de novembro de 2011. A alteração no padrão de financiamento das IES privadas promoveu uma mudança significativa no modelo de gestão: o papel que antes era predominantemente exercido por mantenedoras, de caráter familiar ou religioso, hoje passou a ser de responsabilidade de bancos ou fundos de investimentos que contratam executivos como seus representantes, padronizam procedimentos de relações de trabalho nos departamentos de recursos humanos e prestam contas ao fundo de ações. Decorre daí um perfil de gestão alinhavado com a lógica empresarial, sob responsabilidade de executivos, e muito distante dos objetivos educacionais que sempre foram sustentados por professores e pesquisadores (SOUZA, 2011).

É importante destacar que várias IES do setor privado, hoje, têm seu capital negociado na Bolsa de Valores, pois formam oligopólios financeiros que "juntos possuem mais de um bilhão de reais para investir em aquisições, cujo segmento cresce a cada dia. Para 2011 e 2012 
há perspectivas e possibilidades de 150 negócios de fusões e aquisições do setor" (BRAGA, 2011, p. 15-16).

O Gráfico 01, a seguir, demonstra em números a situação atual dos lucros, no ranking do mercado de capitais, das empresas que dominam o setor das Instituições de Ensino Superior privado, no Brasil, hoje. Vale ressaltar que a Estácio, ao "herdar" alunos de uma instituição descredenciada pelo $\mathrm{MEC}^{9}$, encontra-se entre as dez mais bem cotadas instituições brasileiras, no que respeita ao bom desempenho financeiro e seu valor de mercado na BV. Tal afirmação é ratificada pelos dados apresentados, a seguir:

\section{Gráfico 1 - Ranking do valor das Instituições Privadas}

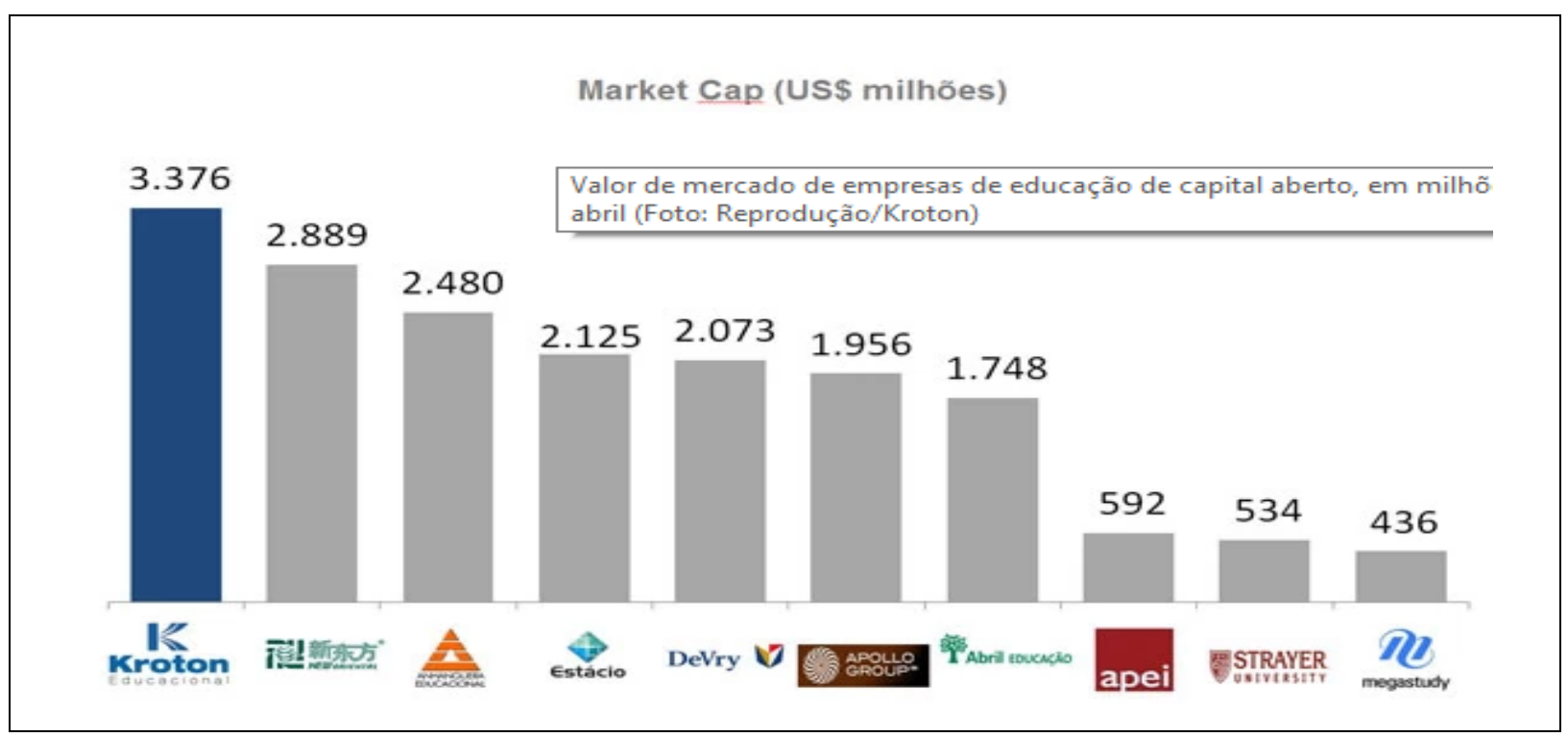

Fonte: Disponível em: <http://g1.globo.com/economia/negocios/noticia/2013/04/rede-de-ensino-kroton-vaiincorporar-anhanguera-em-acordo-com-acoes.html $>$

Chamamos atenção para o fato de que esse processo de compra de IES privadas por empresas de fundos de investimentos tem sido alvo de crítica por parte dos pesquisadores, professores, dos sindicatos e de alguns congressistas, preocupados com as consequências desse processo e principalmente preocupados com a "qualidade" da educação que está sendo “oferecida" por esses oligopólios.

A seguir, destacamos um texto que dá notícia das preocupações de alguns segmentos nacionais diante do fato que acabamos de expor, pelos motivos óbvios:

\footnotetext{
${ }^{9}$ Universidade Gama Filho, fundada em 1939, funcionou até 2013, sendo descredenciada em 13.01.2014.
} 
Contee $^{10}$ denuncia formação de oligopólio no ensino superior durante audiência no Senado

A coordenadora-geral da Contee, Madalena Guasco Peixoto, denunciou hoje (10), no Senado Federal, a financeirização e desnacionalização do ensino superior no Brasil, onde, além de 74\% das matrículas estarem concentrados nas instituições privadas, há exemplos alarmantes de formação de oligopólios na educação. É o caso, por exemplo, do ABC paulista, onde todas as instituições de ensino superior atualmente fazem parte do grupo Kroton. [...]. O panorama ficou ainda mais claro com a fala da professora Madalena Guasco, que reiterou as posições já manifestadas pela Contee a respeito da forma e do conteúdo que têm imperado na expansão da educação superior. Madalena relembrou a expansão privatista da década de 1990 - situação reforçada pela própria Lei de Diretrizes e Bases - e o fato de que só após 2002 a rede pública passou a ser expandida. [...] Ao defender o incremento e fortalecimento da educação pública e criticar a retirada, do novo PNE, da palavra "pública" e sua substituição pelo termo "gratuita", o que incentiva a expansão via Fies e ProUni, a coordenadora-geral da Contee denunciou ainda o processo de desnacionalização e financeirização intensificado a partir de 2005, com a mudança do perfil da educação superior pelos grandes grupos de capital aberto, que acentuaram o fator mercadológico. "Toda a sociedade deveria ficar preocupada com a fusão entre Kroton e Anhanguera", afirmou. "Como podemos ficar tranquilos quando 1 milhão de jovens estão num grupo de capital aberto cuja preocupação não é a qualidade da educação nem a formação de cientistas, mas a valorização de suas ações na bolsa de valores? Essa não é uma questão apenas de mercado, para o CADE regular. É uma questão de soberania nacional" (DA REDAÇÃO, 2013.)

Mais grave do que isso é a situação dos profissionais da educação, ou seja, a presença desses oligopólios apresenta um rol de significativas alterações de caráter negativo para o trabalho do professorado, uma vez que:

O trabalho docente tem representado fonte de lucro aos empresários da educação, que gerenciam as instituições sob a tutela da regulação autoritária do capital. Esses grupos focam em resultados e não em processos. Assim, as condições de intensificação e precarização do trabalho docente se tornam cada vez mais presentes (SANTOS; CHAVES, 2013, p. 76).

Diante do exposto até aqui, concordamos com as críticas feitas pelos autores elencados, especialmente porque entendemos que esse processo vem transformando o setor educacional em uma atividade mercantil, cujos institutos são gerenciados por administradores profissionais, que trazem de empresas do mercado aberto uma expressiva "contribuição para racionalizar custos, [e] otimizar recursos" [...] (BITTAR; RUAS, 2012, p. 126). Assim, a meta vai sempre ser o lucro, ficando a educação no segundo plano.

\section{A mercantilização da educação superior e as leis flexíveis no Brasil neoliberal}

Nosso estudo constata que tais procedimentos têm acontecido em virtude de ainda não haver uma legislação específica que regule o movimento de compra e a venda de IES privadas brasileiras por capital estrangeiro. Lembramos que ainda está tramitando no Congresso Nacional o Projeto de Lei n. ${ }^{\text {7 }}$ 7200/2006, de Reforma da Educação Superior, que propõe uma

${ }^{10}$ Confederação Nacional dos Trabalhadores em Estabelecimentos de Ensino. 
limitação de $30 \%$ do capital das IES para os grupos estrangeiros, conforme vemos a seguir no Art.7, incisos 4 e 5, desse Projeto de Lei, encaminhado ao Congresso desde o governo Lula.

$\S 4 .^{\circ}$ - Em qualquer caso, pelo menos $70 \%$ (setenta por cento) do capital votante das entidades mantenedoras de instituição de ensino superior, quando constituídas sob a forma de sociedade com finalidades lucrativas, deverá pertencer, direta ou indiretamente, a brasileiros natos ou naturalizados.

$\S 5 .^{\circ}$ - É vetada a franquia na educação superior.

Nesse sentido, entendemos que a mercantilização, sendo o "mecanismo pelo qual tudo tende a se transformar em mercadoria no modo de produção capitalista" (OYAMA, 2012, p. 82), atinge agora a educação; e essa mercantilização tem sido aprofundada em nosso país por meio das aquisições por Fundos Private Equity e consequentemente, a partir de 2007, pela abertura do capital dessas empresas educacionais (IPO) ${ }^{11}$. Assim, Carvalho (2013) aponta que esses fundos têm condições de injetar uma significativa quantidade de recursos em seus negócios educacionais, bem como promovem a reestruturação baseada na redução de custos, na racionalização administrativa e, principalmente, “na 'profissionalização' da gestão das instituições de ensino, numa perspectiva claramente empresarial” (OLIVEIRA, 2009, p. 743).

A partir de 2007, com a abertura do capital e da oferta pública inicial (IPO) de ações na Bovespa, as empresas foram classificadas em "nível 2" de governança corporativa, ou seja, elas são enquadradas, tendo, portanto, obrigações adicionais relativas aos direitos dos acionistas e do conselho de administração. São elas: Universidade Anhanguera, Universidade Estácio de Sá, Faculdade Pitágoras e o Sistema COC de Educação e Comunicação, que, ao serem convertidas em Sociedades Anônimas, tiveram suas razões sociais alteradas para: Anhanguera Educacional S.A., Estácio de Sá Participações S.A., Kroton Educacional S.A. e Sistema Educacional Brasileiro S.A. Assim, nos últimos anos, o setor movimentou R \$11 bilhões, em um total de 27 transações, envolvendo, sobretudo, o ensino superior.

A dimensão capitalista que essas instituições estão alcançando pode ser constatada a seguir, mediante os dados resultantes da fusão da Kroton com Anhanguera Educacional, que se tornou a $17^{\mathrm{a}}$ maior "empresa" na Bovespa.

Kroton e Anhanguera confirmam fusão e criam gigante da educação, com valor de $R$ \$ 22 bi

São Paulo - Os acionistas dos grupos Kroton e Anhanguera aprovaram, na última semana, uma fusão que cria a maior empresa brasileira na área do ensino superior. O Conselho Administrativo de Defesa Econômica (CADE), órgão antitruste do governo brasileiro, já havia

${ }^{11}$ IPO é sigla formada pelas iniciais da expressão inglesa Initial Public Offering (Oferta Pública Inicial). Essa oferta se refere à primeira oferta de ações de uma empresa, quando ela abre seu capital e passa a vender suas ações na bolsa de valores [...]. Disponível: <http://www.ipea.gov.br/desafios/index.php? option=com_content $\&$ view=article $\& i d=2074$ : catid=28\&Itemid=23>. Acesso em: dez. 2014. 
autorizado a transação em maio. A confirmação do negócio foi o desfecho de uma negociação que durou mais de um ano e cria um grupo com valor de mercado de aproximadamente $\mathrm{R} \$ 22$ bilhões, além de quase 1 milhão de alunos matriculados. \# O Brasil tem cerca de 2 mil faculdades e universidades particulares de graduação, que reúnem cerca de 5 milhões de alunos; somados os alunos da rede pública, a população universitária brasileira está em torno de 7 milhões de alunos, um sétimo deles estudando em instituições do novo conglomerado, que manterá o nome Kroton. \# A decisão dos acionistas se deve, principalmente, às condições que o mercado de educação superior encontra desde a criação do Prouni, em 2004. As bolsas oferecidas pelo programa, que vão do valor integral da mensalidade para os alunos com renda familiar de até 1,5 salário mínimo a bolsas parciais, para quem tem renda familiar de até três salários mínimos, representam para o setor privado uma renda fixa, de um pagador com credibilidade e facilmente acionável por meio do Judiciário e de outros mecanismos de controle. \# Além disso, o programa fez disparar as matrículas nas entidades privadas. Somente a edição do primeiro semestre de 2014 do Prouni superou o número total de candidatos do ano passado, incluídos os de matrícula no meio do ano, com 1,3 milhão de inscritos. \# O recorde anterior era do Prouni de janeiro de 2012, com 1,2 milhão de candidatos. São oferecidas bolsas em 1.116 instituições participantes em 991 municípios. Desde a criação do programa, mais de 1,5 milhão de brasileiros conquistaram o diploma universitário (ALERIGI JÚNIOR; GOY, SCHINCARIOL, 2014).

Assim, podemos afirmar que ascensão dos processos de financeirização da educação superior no Brasil tem como único objetivo atender aos interesses meramente mercantis. Santos e Chaves (2013, p. 76) destacaram que a abertura de capital revela "a voracidade do mercado e consolida o gigantismo econômico-financeiro, inclusive para a entrada de capital estrangeiro na educação", conforme apresentado neste artigo.

Novamente a questão dos oligopólios da educação superior ganha centralidade no noticiário, em virtude da proposta de Kroton Educacional S.A. fundir suas ações com Estácio de Sá Participações S.A. Essa fusão vai permitir a criação da maior empresa de ensino superior privado do mundo, conforme reportagem a seguir:

Kroton avalia compra da Estácio para criar gigante de 1,6 milhão de alunos

Três anos após adquirir a Anhanguera e criar a maior empresa de ensino superior privado do mundo, a Kroton anunciou que planeja incorporar a $2^{\mathrm{a}}$ empresa do ranking. [...]. Nesta quintafeira, 2, a maior companhia de ensino privado do País voltou a mostrar que o seu apetite por aquisições está longe de acabar: a empresa informou ao mercado a intenção de incorporar a Estácio Participações, a segunda maior do ranking, com seus quase 600 mil estudantes. Em fato relevante à Comissão de Valores Mobiliários (CVM), a Kroton anunciou que está avaliando a compra da concorrente em uma operação envolvendo apenas ações. A empresa disse ainda que já contratou o Itaú BBA e o escritório de advocacia Barbosa Müssnich Aragão para assessorá-la em uma eventual transação. [...]. Barreiras. O processo, que pode gerar ganhos de sinergias estimados em até $\mathrm{R} \$ 8$ bilhões, deve precisar superar, assim como ocorreu há três anos, eventuais divergências de acionistas e restrições do CADE. Assim como no caso da Anhanguera, a Estácio é uma empresa de capital pulverizado e sem controlador definido. A concretização do negócio depende, portanto, da base de acionistas minoritários, formada sobretudo por fundos como o Coronation e a Oppenheimer (SOUSA, 2016).

Entretanto, Kroton enfrenta obstáculos para concretização do negócio, uma vez que as ações de Estácio de Sá Participações S.A. são pulverizadas, não detendo um único controlador. Além disso, há pressão de outro concorrente na disputa. Assim, o Grupo Ser 
Educacional ${ }^{12}$ fez um comunicado sobre uma propositura de "combinação de negócio" com a Estácio Participações S.A. e, se realmente o negócio for concretizado, "a nova instituição teria 750 mil alunos - sendo 600 mil da Estácio e 150 mil do Grupo Ser Educacional” (SORIMA NETO, Seção Economia, 06 de junho de 2016).

Afirmamos, entretanto que este processo não está isento de questionamento por parte de vários setores da sociedade brasileira, preocupados com a criação dessa gigante educacional.

\section{OAB RIO vai ao CADE contra possível fusão entre Kroton e Estácio}

São Paulo - A Ordem dos Advogados do Brasil (OAB), do Rio de Janeiro, entrou com medida no Conselho Administrativo de Defesa Econômica (CADE) contra uma possível fusão entre Kroton e Estácio. “Ao neutralizar esta competição, abre-se espaço para aumentos abusivos de preços e para precarização do ensino. O monopólio inibe as condições benéficas que estimulam as melhorias do serviço advindas de um ambiente sadio de disputa", segundo o procuradorgeral da OAB-RJ, Fábio Nogueira. A OAB-RJ cita ainda levantamento da Educa Insights que mostra concentração de $30 \%$ em 75 cidades brasileiras. Deste total, 69 referem-se à concentração ensino à distância e as outras seis em cursos presenciais. A entidade pontua também que houve "prejuízos socioeconômicos ao Estado provados pelo fim das universidades Gama Filho e Cidade por conta das aquisições desastrosas que tratam a educação como mera mercadoria" A Universidade Gama Filho e o Centro Universitário Cidade foram descredenciados pelo Ministério da Educação (MEC) em 2014. Os alunos do curso de medicina da Gama Filho foram transferidos justamente para a Estácio. Os estudantes dos demais cursos foram para a Universidade Veiga de Almeida e Faculdade de Tecnologia Senac Rio (FATEC) (KOIKE, 2016).

Além da $\mathrm{OAB}$, e de alguns congressistas, todos preocupados com as "possíveis consequências" dessa fusão, destacamos as críticas que os alunos da Estácio vêm fazendo em relação a este processo, uma vez que uma das partes, a mais afetada, não teria recebido nenhuma informação sobre o processo de fusão das empresas e de como essa aquisição poderá afetar os alunos e seus respectivos financiamentos estudantis, mas também e principalmente o corpo docente e os colaboradores do setor administrativo.

\footnotetext{
Alunos da Estácio e OAB entram com medidas judiciais contra fusão com multinacional Kroton

Uma ação civil pública contra a Estácio foi protocolada nesta segunda-feira (4), pela Federação Nacional dos Alunos e Ex-Alunos de Direito da Universidade Estácio de Sá, após a empresa divulgar que será negociada com a Kroton. A ação, protocolada no Tribunal de Justiça do Rio de Janeiro, busca a explicação da Estácio sobre os assuntos relacionados à fusão. Segundo o advogado dos estudantes, Victor Travancas, os alunos ficaram sabendo da venda pela imprensa e, desde então, a empresa não fez nenhum comunicado direcionado aos estudantes. "Temos insistentemente tentado falar com o diretor presidente da Estácio e ele não responde, se nega a nos receber. São os alunos que pagam a mensalidade, eles não podem ficar reféns da Estácio diante dessas mudanças", afirmou Travancas. O advogado conta que, especialmente para os alunos do Rio de Janeiro, a falta de um comunicado da Estácio é angustiante. "Muitos alunos da universidade Gama Filho, que fechou, foram transferidos para a Estácio pelo Ministério da Educação. Um dia os alunos chegaram para estudar e não tinha mais Gama Filho”. A Ordem
}

\footnotetext{
${ }^{12}$ Empresa de Educação Superior Privado com presença em 28 cidades de 12 estados do Brasil.
} 
dos Advogados do Brasil do Rio de Janeiro (OAB-RJ) entrou com uma medida no Conselho Administrativo de Defesa Econômica (Cade) contra o interesse da Kroton em adquirir a Estácio, em meados de junho. A Ordem alega que a operação trará concentração econômica ilegal ao mercado, de mais de $30 \%$, diante de um limite estabelecido pelo Cade de $20 \%$ (UMES, 2016).

Nesse sentido, entendemos que a criação dos oligopólios na educação superior é fruto de novos formatos institucionais e administrativos, que favorecem a entrada de capital estrangeiro no país para sua respectiva expansão. A própria transnacionalização da educação superior na perspectiva do mercado aponta para uma séria problemática no campo do trabalho, se levarmos em conta que isso resulta na "categorização da comercialização/ mercantilização/ mercadorização da educação superior” (TAVARES; MAUÉS, 2012, p. 41), que vai formar profissionais com frágeis critérios técnico-teóricos.

\section{Considerações finais}

O artigo expõe que o papel desempenhado pela reestruturação do Estado brasileiro e, consequentemente, os novos arranjos para o campo da educação foram responsáveis pela emergência dos grandes oligopólios da educação superior privada, uma vez que as políticas que vêm regendo a Educação são de cariz neoliberal. $O$ estudo destaca ainda que, neste cenário, a educação superior brasileira passou por novos rearranjos, os quais contribuíram para o encaminhamento sem barreiras da privatização da educação superior em nosso país.

Leite e Genro (2012) afirmam que o século XXI é marcado por um novo direcionamento que vai exigir que as universidades se abram para os mercados globais e internacionais, visando desenvolver o capitalismo acadêmico. Para colocar tal empreitada em vigor, tanto o Brasil quanto os demais países da América Latina, colocaram em prática reformas no ensino superior, sendo que tais iniciativas tiveram como consequências:

Expansão do sistema educativo privado; ampliação do acesso e das matrículas com oferta maior na rede privada; cobrança de taxas de matrícula; diferenciação salarial entre os acadêmicos; introdução de sistema merit pay; realocação de recursos públicos; alteração dos percentuais orçamentários de cada país para os diferentes níveis de ensino com menor percentual para a Educação Superior; submissão de políticas públicas às recomendações de órgãos financeiros internacionais (LEITE; GENRO, 2012, p. 764).

Entretanto, é importante salientar que as mudanças pelas quais passa a educação superior estão intimamente atreladas ao processo de globalização que se apoia em políticas neoliberais, e serão essas políticas que vão orientar o campo educacional. Nesse sentido, concordamos com Leite e Genro (2012, p. 765) que destacam que "tais reformas, em verdade, colocaram a IES na rota dos processos de globalização”. 
Essa nova hegemonia global vai ganhar novos contornos na atualidade, pois assume um "viés benevolente" (HARTMANN, 2008), tendo como expressão máxima a Comunidade Europeia (CE), em especial com o setor educativo que será estabelecido por meio do Processo de Bolonha, que pode ser caracterizado como "fenômeno de deslocação do processo de formação das políticas para a educação em direção ao nível supranacional” (ANTUNES, 2006, p. 65; DIAS SOBRINHO, 2005, p. 169-195).

Leite e Genro (2012, p. 770) destacam em suas análises que a opção de implementar uma política internacional de educação superior tem como finalidade [...] "atingir o mundo na totalidade", incluindo a América Latina e o Caribe, e expressa o exercício de poder europeu numa busca para atingir interesses capitalistas através de corações e mentes. Entretanto, Antunes (2006a), Lima, Azevedo e Catani (2008, p. 12) ressaltam que na verdade o Processo de Bolonha tem desencadeado um movimento de desnacionalização da educação superior, uma europeização das instituições de ensino superior e, mais do que isso, esse fenômeno tem optado [...] "por políticas de liberalização e pela necessária harmonização para a emulação e a competitividade, vencendo barreiras e fronteiras tradicionais".

No entanto, para compreender as transformações da educação superior, ocorridas em âmbito global, com incidência no Brasil, recorremos ao conceito de capitalismo acadêmico, desenvolvido por de Slaughter e Leslie (1997) e que pode ser mais bem compreendido,

a partir del reconocimiento del crecimiento de los mercados globales, el desarrollo de políticas nacionales centradas en la investigación aplicada y la innovación, la reducción del monto de subsidio directo del Estado a las instituciones, y el incremento de los vínculos de los académicos con el mercado (COLADO, 2003, p. 1059). ${ }^{13}$

Assim, a premissa básica é converter a universidade em uma espécie de empresa lucrativa que, como as demais empresas que operam no mercado, procura otimizar seus recursos para conseguir a maximização dos lucros. Portanto, o "capitalismo académico se refiere al uso que las universidades hacen de su único activo real, el capital humano de sus académicos, con el propósito de incrementar sus ingresos; tiene que ver con un conjunto de iniciativas y comportamientos económicos [...]"14 (COLADO, 2003, p. 1059).

13 a partir do reconhecimento do crescimento dos mercados globais, o desenvolvimento de políticas nacionais centradas na pesquisa aplicada e de inovação, reduzindo o montante da subvenção direta do Estado às instituições, e o aumento de vínculos entre os universitários e o mercado (tradução livre)

${ }^{14} \mathrm{O}$ capitalismo acadêmico refere-se ao uso que as universidades fazem de seu único ativo real, ou seja, o capital humano de seus acadêmicos, cujo propósito é o de aumentar sua renda, por meio de um conjunto de iniciativas e comportamentos econômicos (tradução livre) 
Além disso, Delgado (2006, p. 101) chama atenção para o fato de que os impactos decorridos do capitalismo acadêmico tenham resultados nefastos para as humanidades, principalmente para a formação intelectual do pensamento crítico, pois as pesquisas, em parcerias com grandes empresas, migram para o setor tecnológico de desenvolvimento de produtos e do agronegócio, deixando de lado a filosofia e as ciências sociais. Nesse sentido, ele esclarece que:

Este proyecto, por supuesto, tiene efectos derivados para las universidades públicas que empiezan a destinar más recursos a la investigación aplicada — que resuelve problemas específicos de uma u otra empresa privada, la que pague el servicio- que a la ciencia básica - cuyo fin es atender al desarrollo de la ciencia y producir conocimientos sin destinatario particular-, además de aumentar los recursos destinados a las ciencias naturales y a la innovación tecnológica, limitando aquellos orientados al desarrollo de las ciencias sociales y las humanidades. En este proceso, las grandes perdedoras resultan ser la investigación científica, la educación que forma intelectual y culturalmente a los jóvenes y, particularmente, el pensamiento crítico, todos ellos -investigación científica, formación intelectual y pensamiento crítico - convertidos en una especie de lastre para la "modernidad y la competitividad" de las universidades —en tanto ninguna contribuye a obtener el ISO 9000-, cuyo propósito fundamental es ahora ganar mercados, lo que según muchos nuevos funcionarios universitarios es lo único que puede dar viabilidad a la universidad pública del siglo XXI. ${ }^{15}$

A formação dos oligopólios precisaria ser investigada no que diz respeito a implicações desse processo no trabalho docente, que, ao que tudo indica, passará por um processo cada vez maior de precarização. Veremos docentes sendo demitidos para serem recontratados com hora/aula de menor valor? A qualidade do ensino ofertado aos estudantes se deteriorará e teremos o aprofundamento quantitativo das certificações em detrimentos de uma formação de qualidade? E qual será o impacto da ação desses oligopólios na educação superior brasileira de uma maneira geral?

As primeiras experiências dos oligopólios da educação superior privada começam a serem investigadas pelos pesquisadores, pois compreendemos que existe uma símil prática comum às grandes empresas de educação superior que não se tornaram oligopólios, mas que estão agindo dentro da mesma lógica.

${ }^{15}$ Este projeto, evidentemente, tem efeitos decorrentes para as universidades públicas que começam a destinar mais recursos para a pesquisa aplicada - que resolve problemas específicos de uma ou outra empresa privada, aquela que pague pelo serviço - do que para as ciência básica - cujo objetivo é atender ao desenvolvimento da ciência e produzir conhecimento sem destinatário particular - além de aumentar os recursos destinados às ciências naturais e à inovação tecnológica, limitando os recursos que seriam destinados para o desenvolvimento das ciências sociais e humanas. Neste processo, as grandes perdedoras parecem ser a pesquisa científica, a educação que forma intelectual e culturalmente aos jovens e, particularmente, o pensamento crítico, todas elas - pesquisa científica, formação intelectual e pensamento crítico - categorias transformadas em uma espécie de lastro para a "modernidade e a competitividade" das universidades; porém, como nenhuma delas contribui para a obtenção da ISO 9000, cujo objetivo principal agora é o de ganhar mercados, o que para muitos novos funcionários da universidade será a única coisa que pode dar viabilidade à universidade pública do século XXI. (tradução livre) 
Cabe-nos indagar acerca do próprio sentido da educação superior que, a cada dia mais comprometido, perde seu princípio fundamental - que é o de contribuir para a emancipação do indivíduo e a formação de uma pessoa crítica - mas que está sendo deixado de lado em prol do lucro, com a transformação da educação superior em mercadoria que produz um ensino aligeirado no sentido de fornecer um diploma cada vez mais desvalorizado no próprio mercado de trabalho (certificação vazia).

\section{Referências}

ALERIGI JÚNIOR, Alberto; GOY, Leonardo; SCHINCARIOL, Juliana. Kroton e Anhanguera têm sinal verde para grupo de R \$22 bi. Exame, São Paulo, 2014. Disponível em: <http://exame.abril.com.br/negocios/noticias/kroton-e-anhanguera-tem-sinal-verde-paragrupo-de-r-22-bi> Acesso em: 15 jan. 2015.

ANTUNES, F. Governação e espaço europeu de educação: regulação da educação e visões para o projecto "Europa". Revista Crítica de Ciências Sociais, Coimbra, n. 75, p.63-93, 2006. Disponível em: <https://repositorium.sdum.uminho.pt/bitstream/1822/24468/1/ RCCS\%2075\%20FAntunes.pdf >. Acesso em:10 jul. 2016.

BARREYRO, Gladys Beatriz. Mapa do ensino superior privado. Brasília (DF): Instituto Nacional de Estudos e Pesquisas Educacionais Anísio Teixeira, 2008. Disponível em: <http://bibliotecadigital.puc-campinas.edu.br/services/e-books /Relatosdepesquisa37.pdf>. Acesso em 25 jun. 2014.

BITTAR, Mariluce; RUAS, Claudia Mara Stapani. Expansão da educação superior no Brasil e a formação de oligopólios. Hegemonia do setor privado mercantil. Eccos Revista Científica, São Paulo, n. 29, p. 115-133, set./dez. 2012. Disponível em: <http://www.redalyc.org/pdf/715/ 71524734007.pdf>. Acesso em: 25 set. 2014.

BRAGA, Ryon. Ensino superior: perspectivas para 2011. Revista Linha Direta, Belo Horizonte, v. 14, n. 155, p. 12-46, fev. 2011. Disponível em: <http://www.linhadireta. com.br/revistas/arquivos/Revista_155.pdf>. Acesso em: 25 set. 2014.

BRASIL. MEC. Decreto n 2.306, de 19 de agosto de 1997. Regulamenta, para o Sistema Federal de Ensino, as disposições contidas no art. 10 da Medida Provisória $n^{\circ} 1.477-39$, de 8 de agosto de 1997, e nos Arts. 16, 19, 20, 45, 46 e $\S 1^{\circ}, 52$, parágrafo único, 54 e 88 da Lei n ${ }^{\circ}$ 9.394, de 20 de dezembro de 1996, e dá outras providências. Disponível em: <http://www.planalto.gov.br/ccivil_03/decreto/D2306.htm>. Acesso em: 25 out. 2012.

CARVALHO, Cristina Helena Almeida de. A mercantilização da educação superior brasileira e as estratégias de mercado da IES lucrativas. Revista Brasileira de Educação, Rio de Janeiro, v. 18, p. 761-776, 2013. Disponível em: <http://www.scielo.br/pdf/rbedu/v18n54/13.pdf>. Acesso em: 23 set. 2014.

CHAVES, Vera Lucia Jacob. Expansão da privatização/ mercantilização do ensino superior brasileiro: a formação dos oligopólios. Educação \& Sociedade, Campinas, v. 31, n. 111, p. 481-500, abr./jun. 2010. Disponível em: <http://www.scielo.br/pdf/es/v31n111/ v31n111a10.pdf>. Acesso em: 24 ago. 2014.

COLADO, Eduardo Ibarra. Capitalismo académico y globalización: La universidad reinventada. Revista Educação em Sociedade, Campinas, v. 24, n. 84, p. 1059-1067, set. 
2003. Disponível em: <http://www.scielo.br/pdf/es/v24n84/a17v2484.pdf>. Acesso em: 15 jun. 2016.

DA Redação. Agência do Senado. Contee denuncia formação de oligopólio no ensino superior durante audiência no senado. Brasília, 10 jul. 2013. Disponível em: <http://contee.org.br/contee/index.php/2013/07/contee-denuncia-formacao-de-oligopolio-noensino-superior-durante-audiencia-no-senado/\#.V4KFMvkrLIU> Acesso em: 23 jun. 2014.

DELGADO, Jaime Ornellas. Neoliberalismo y Capitalismo académico. Facultad de Economía de la Benemérita Universidad Autónoma de Puebla. Puebla de Zaragoza, México, 2006. Disponível em: 〈http://biblioteca.clacso.edu.ar/ar/libros/grupos/gentili/cap3.pdf>. Acesso: 15 jun. 2016.

DIAS SOBRINHO, José. Dilemas da educação superior no mundo globalizado: sociedade do conhecimento ou economia do conhecimento? São Paulo: Casa do Psicólogo, 2005.

ERTHAL, João Marcelo; PEROZIM, Lívia. O ensino vai à bolsa. Revista Carta Capital, São Paulo, n. 466, 2007. Disponível em: <http://aberrablog.blogspot.com.br/2007/10/oensino-vai-bolsa.html>. Acesso em: ago. 2014.

FBV: DeVry Brasil amplia participação no Nordeste e chega a Recife com a Faculdade Boa Viagem (FBV). Salvador, 15 jan. 2015. Disponível em:

$<$ http://www.devrybrasil.edu.br/frb/noticias/devry-brasil-amplia-participacao-no-nordeste-echega-recife-com-faculdade-boa-viagem> Acesso em: 15 nov. 2014.

GOIS, Ancelmo; TAKAHASHI, Fábio. Grupo dos EUA compra a Anhembi Morumbi. Folha de S. Paulo, de 02 de dezembro de 2005. Disponível em:

<http://www1.folha.uol.com.br/folha/educacao/ult305u18114.shtml> Acesso em: 15 set. 2014.

HARTMANN, Eva. Bologna goes global: a new imperialism in the making? Globalisation, Societies and Education, London, v. 6, n. 3, p. 207-220, 2008. Disponível em:

$<$ https://www.researchgate.net/publication/263244732_Bologna_goes_global_a_new_imperia lism_in_the_making> Acesso em: 10 out. 2015.

KOIKE, Beth. OAB Rio vai ao CADE contra possível fusão entre Kroton e Estácio. São Paulo, 15 jun. 2016. Disponível em: <http://www.valor.com.br/empresas/4601529/oab-riovai-ao-cade-contra-possivel-fusao-entre-kroton-e-estacio> Acesso em: 15 jun. 2016.

KROTON e Anhanguera Educacional fazem acordo de associação. G1, São Paulo, 22 abr. 2013. Disponível em: <http://g1.globo.com/economia/negocios/noticia/2013/04/rede-deensino-kroton-vai-incorporar-anhanguera-em-acordo-com-acoes.html> Acesso em: out.2015.

KROTON EDUCACIONAL S.A E CONTROLADAS. Demonstrações financeiras referentes ao exercício findo em 31 de dezembro de 2012. Disponível em:

$<$ http://www.mzweb.com.br/kroton2010/web/download_arquivos.asp?id_arquivo=F18821003C6F-418F-BBB3-46AF0FCD0C7F> Acesso em: 15 de jun.2016.

LEITE, Denise. Brazilian Higher education from a post-colonial perspective. Globalization, Societies and Education, London, v. 8, n. 2, p. 219-233, jun. 2010. Disponível em:

$<$ http://cienciaparaeducacao.org/eng/publicacao/leite-denise-brazilian-higher-education-froma-postcolonial-perspective-globalisation-societies-and-education-v-8-p-219-233-2010/>.

Acesso em: 15 jun. 2016.

LEITE, Denise; GENRO, Maria Elly Herz. Avaliação e internacionalização da Educação superior: Quo vadis América Latina? Avaliação, Campinas; Sorocaba, v. 17, n. 3, p. 763-785, 
nov. 2012. Disponível em: <http://www.scielo.br/pdf/aval/v17n3/a09v17 n3.pdf>. Acesso em: 15 jun. 2016.

LIMA. Licínio C.; AZEVEDO, Mario Luiz Neves de; CATANI, Afrânio Mendes. O Processo de Bolonha, a avaliação da educação superior e algumas considerações sobre a Universidade Nova. Avaliação, Campinas; Sorocaba, v. 13, n. 1, p. 7-36, mar. 2008. Disponível em: <http://www.scielo.br/pdf/aval/v13n1/a02v13n1.pdf>. Acesso em: 15 jul. 2016.

LEHER, Roberto. TLC, política externa brasileira e a mercantilização da educação. Rio de Janeiro: UERJ, 2005. Disponível em <http://www.lpp-buenosaires.net/ outrobrasil/docs/15122005152849_An\%C3\%A1lise_rleher_2dez05.doc> Acesso em: 24 set. 2014.

MEIRELLES, Jorge Luís Faria; PIMENTA JÚNIOR, Tabajara. REBELATTO, Daisy Aparecida do Nascimento. Venture capital e private equity Brasil: alternativa de financiamento para empresas de base tecnológica. Revista Gestão e Produção, São Carlos, v. 15, n. 1, p. 11-21, jan - abr.2008. Disponível em:

<http://www.scielo.br/pdf/gp/v15n1/a03v15n1.pdf> Acesso em: 15 ago. 2016.

OSCAR, Nayana; SOUSA, Dayanne. Grupo americano, dono da Anhembi Morumbi compra FMU por R \$1 bi. O Estado de S. Paulo, São Paulo, 22 de ago. 2013. Seção Economia Negócios. Disponível em: <http://economia.estadao.com.br/noticias/negocios,grupoamericano-dono-da-anhembi-morumbi-compra-fmu-por-r-1-bi,162651e>. Acesso em: 12 set. 2014.

OLIVEIRA, Portela Romualdo. A transformação da educação em mercadoria no Brasil.

Revista Educação e Sociedade, Campinas, v. 30, n. 108, p. 739-760, out. 2009. Disponível em: 〈http://www.redalyc.org/pdf/873/87313700006.pdf> acesso em: 16 ago. 2016.

OYAMA, Edison Riuitiro. O negócio da educação superior: da educação-mercadoria ao capital financeiro. In: RODRIGUES, José (Org.). A universidade brasileira rumo à Nova América: pós-modernismo, shopping center e educação superior. Niterói: EDUFF, 2012. p.79-110

PAULA, Maria Fátima Costa de. A modernização da Universidade e a transformação da intelligentzia universitária: casos USP e UFRJ. 1. ed. Florianópolis: Insular, 2002. v. 1.

PAULA, Maria de Fatima. Costa de. A perda da identidade e da autonomia da universidade brasileira no contex to do neoliberalismo. Avaliação, Campinas; Sorocaba, v. 8, n. 4, p. 53-67, 2003.

SANTOS, Aline Veiga dos; CHAVES, Vera Lúcia Jacob. Formação dos oligopólios na educação superior privada brasileira: sobre implicação no trabalho docente. Revista Educação em Questão, Natal, v. 46, n. 32, p. 75-97, maio/ago. 2013. Disponível em: <http://periodicos.ufrn.br/educacaoemquestao/article/download/5123/4101>. Acesso em: 12 set. 2014.

SGUISSARDI, Valdemar. Modelo de expansão da educação superior no Brasil: predomínio privado/mercantil e desafios para a regulação e a formação universitária. Revista Educação e Sociedade, Campinas, v. 29, n. 105, p. 991-1022, set./dez. 2008. Disponível em: <http://www.scielo.br/pdf/es/v29n105/v29n105a04.pdf> Acesso em: 22 set.2014.

SILVA JUNIOR, João dos Reis; SGUISSARDI, Valdemar (Orgs.). Educação Superior: análise e perspectiva de pesquisa. São Paulo: Xamã, 2001. 
SLAUGHTER, Sheila; LESLIE, L.L. Academic capitalism: politics, policies and the entrepreneurial university. Baltimore: Johns Hopkins, 1997.

SORIMA NETO, João. Grupo Ser Educacional faz proposta de fusão com a Estácio. O Globo, Rio de Janeiro, 05 de junho de 2016, seção economia. Disponível em: $<$ https://oglobo.globo.com/economia/grupo-ser-educacional-faz-proposta-de-fusao-comestacio-19447643> Acesso em: 15 jun. 2016.

SOUZA, Andrea Harada. Da educação mercadoria à certificação vazia. Le Monde Diplomatique Brasil, São Paulo, 1 dez. 2011. Disponível em:

<https://www.diplomatique.org.br/print. php?tipo=ar\&id=1072> Acesso em: 13 set. 2014.

SOUSA, Dayanne. Kroton avalia compra da Estácio para criar gigante de 1,6 milhão de alunos. Estadão, São Paulo, 3 jun. 2016. Disponível em:

$<$ http://economia.estadao.com.br/noticias/negocios,kroton-avalia-compra-da-estacio-paracriar-gigante-de-1-6-milhao-de-alunos,10000054971> Acesso em: 3 jun.2016.

TAVARES, Pedro Henrique de Souza; MAUÉS; Olgaises. Expansão da educação superior pós-IDB de 1996 e constituição oligopólios transnacionais no Estado do Pará. Germinal: Marxismo e Educação em Debate, Salvador, v. 4, n. 1, p. 31-43, jun. 2012. Disponível em: <https://portalseer.ufba.br/index.php/revistagerminal/article/view/9402/6840 >Acesso em: 15 out. 2015.

UMES. Alunos da Estácio e OAB entram com medidas judiciais contra a fusão com a multinacional Kroton. Disponível: <http://umes.org.br/index.php/noticias/1405-alunos-daestacio-e-oab-entram-com-medidas-judiciais-contra-fusao-com-multinacional-kroton> Acesso em: 11 jul. 2016.

${ }^{1}$ Andreia Gomes da Cruz Universidade Federal Rural do Rio de Janeiro | Depto de Educação e Sociedade do Instituto Multidisciplinar Rio de Janeiro | RJ | Brasil. Contato: andreiagomes25@yahoo.com.br ORCID (iD)/https://orcid.org/0000-0002-3953-9199

${ }^{2}$ Maria de Fátima Costa de Paula Universidade Federal Fluminense | Faculdade de Educação | Programa de Pós-graduação em Educação Rio de Janeiro | RJ | Brasil. Contato: mfatimadepaula2015@gmail.com ORCID (iD) http://orcid.org/0000-0003-1659-3384 